\title{
Retrato DE OCCIDEnTE Visto Desde El KREMlin: El Viaje De CÉsar VAllejo a la URSS
}

\author{
Raquel Arias Careaga \\ Universidad Autónoma de Madrid
}

Title: Portrait of the West seen from the Kremlin: César Vallejo's journey to the USSR

\begin{abstract}
The book that César Vallejo wrote after his travels to URSS is a review of different aspects in soviet society. This book, far from appear as a panegyric of socialist social organization, brings several topics to the reader, who must rethink his own culture from another perspective. So, Vallejo exposed several mechanisms of the capitalist system while he supported an inevitable change. Soviet Union appears under a very positive perspective in Rusia en I93 I, but it is not due to a naive attitude of the poet. Instead, he shows a clear conscience about the mistakes of occidental societies to achieve a fairer world, especially to the most disadvantaged segments of the population.
\end{abstract}

Key words: César Vallejo. Soviet Union. Social Criticism. Culture.

El régimen "democrático" burgués, liberal y parlamentario, es una dictadura encubierta, hipócrita, disimulada, façonnée, odiosa. César Vallejo, Rusia en I93I.

A partir de I930, año en que aparece una segunda edición de Trilce, César Vallejo no publicará ningún libro de poesía. Los heraldos negros, publicado en 1919, y Trilce, que se publicó por primera vez en 1922, son los únicos libros de poesía aparecidos en vida del autor peruano. La conmoción provocada por esta poesía inclasificable y profunda ha hecho de Vallejo un autor cuya obra parece muchas veces limitarse a estos dos volúmenes. Pero, aunque es cierto que Vallejo siguió escribiendo poesía hasta el final de su vida como demuestran los Poemas humanos reunidos y publicados tras su muerte, parece que sus intereses tenían más que ver con la prosa a la que dedica sus esfuerzos a partir de este momento. ${ }^{I}$ Escalas melografiadas, cuentos y prosas aparecidos en 1923 y contemporáneos, sin duda, de la escritura

${ }^{1}$ No hay que olvidar, con todo, sus esfuerzos por publicar otro libro de poemas. El 25 de diciembre de 1935 Vallejo (20 I : 332) le comenta a Juan Larrea: “¿Qué es de Bergamín? A propósito, Alberti le escribió sobre mi libro publicable de versos. No sé si Bergamín recibiría esa carta, porque no ha contestado". 
de Trilce, abren una senda en la que encontraremos textos tan importantes como Fabla salvaje, del mismo año i 923 . Esta novela, en la línea bien conocida de la época cuyo afán es universalizar la literatura hispanoamericana, consigue insertar temas muy presentes en la literatura del momento como la locura, el desdoblamiento de la identidad, la anulación del sujeto, y todo ello en un ambiente claramente peruano. ${ }^{2}$ De finales de la década de los años 20 es también Hacia el reino de los Sciris, acercamiento al mundo precolombino, que aunque quedará inacabada, será retomada en la siguiente década, corregida e incluso utilizada como base de una versión teatral, $\mathrm{La}$ piedra cansada.

En I93 I aparece una novela de clara vocación indigenista y social, El tungsteno, donde el acercamiento de Vallejo al marxismo es evidente. ${ }^{3} \mathrm{La}$ escenificación de la lucha de clases en el peculiar ambiente peruano, así como la inclusión de elementos diversos como la penetración del capital y las multinacionales extranjeras, denuncian que la explotación a que son sometidos los trabajadores es uno de los aspectos intrínsecos de la organización social del capitalismo. En la misma línea, pero en un contexto bien distinto, escribe, también en 193 I, Paco Yunque, un cuento que permanecerá inédito hasta i95 r. Vallejo ambienta la lucha de clases en la escuela, y la división establecida entre los alumnos reproduce la estructura social en la que viven. La perspectiva del narrador en tercera persona que, lejos de identificarse con el maestro como podría ser lo esperado, ${ }^{4}$ se aproxima a la del niño que da

${ }^{2}$ Para un análisis más cuidado de estos textos y los que se mencionan a continuación remitimos a la edición de obras en prosa de César Vallejo que hemos preparado para la editorial Akal y que se encuentra actualmente en prensa.

${ }^{3}$ Las posiciones marxistas de César Vallejo no significan una adopción incuestionada de los presupuestos más ortodoxos que podía representar la Unión Soviética. Esta actitud y su relación con el marxismo también heterodoxo de Walter Benjamin puede verse en el artículo de Rafael Gutiérrez Girardot que aparece en la bibliografía.

${ }^{4}$ No en vano Vallejo había sido maestro de primaria. Existe un testimonio entrañable de Ciro Alegría (1978) que nos permite entrever qué tipo de maestro pudo ser el poeta en su juventud. Véase la bibliografía adjunta. 
título al texto, humaniza al objeto de todas las humillaciones y desprecios que leemos en esta historia. Pero no podemos quedarnos en la anécdota del texto. La injusticia de que es objeto el niño es la injusticia que domina toda la sociedad. Gracias a la perspectiva del narrador comprobaremos la victoria moral de Paco Yunque, al mismo tiempo que el lector se siente empujado a defender un imprescindible cambio de las condiciones en que vive la infancia, que no son otras que las que dominan el conjunto social. De nuevo, solo una transformación profunda puede acabar con la indignación que provoca la lectura de esta historia.

De una heterogeneidad muy marcada será el resto de la producción en prosa de Vallejo, reuniendo ensayos, narraciones y reflexiones de todo tipo. De entre ellos nos interesa aquí un conjunto de crónicas ${ }^{5}$ publicadas en diversos medios tanto españoles como peruanos y que serán reunidas después en un volumen titulado Rusia en 193 I (reflexiones al pie del Kremlin). El libro está compuesto por el conjunto de artículos escritos a raíz de dos viajes a la Unión Soviética que Vallejo realizó en 1928 y 1929 . Envió las crónicas al diario El Comercio y a la revista Mundial, publicaciones peruanas, y aparecieron también desde enero de 1930 y a lo largo de la corta vida de la revista española Bolívar, ${ }^{6}$ dirigida por su amigo Pablo Abril de Vivero. La recopilación de todo este material junto con otros textos inéditos se publicó en Madrid en la colección que Ediciones Ulises dedicaba a la "Nueva Política" (Iwasaki, 20 13: 10) y dentro de una corriente de interés apasionado por todo lo relacionado con la Revolución Rusa y sus consecuencias. ${ }^{7}$

${ }^{5}$ Marta Ortiz Canseco (20 I4) ha estudiado las características principales de los artículos periodísticos publicados por Vallejo durante sus años en París y su relación con la visión que de la sociedad francesa y occidental en general se trasluce en los mismos.

${ }^{6}$ Para un reciente análisis de los aspectos más relevantes de esta publicación, tanto desde un punto de vista ideológico como literario y artístico puede consultarse Arias (20 I 7a).

${ }^{7}$ Se puede consultar el comentario y catálogo de obras publicadas en aquellos años en España que presenta Gonzalo Santonja en su libro La República de los libros. El interés por la Unión Soviética consigue aumentar notablemente el número de lectores de aquella época. Véanse, por ejemplo, las referencias en Santonja (I 989: i I, I 3, 35), o la publicación 
No es necesario insistir en este aspecto, ya que autores tan destacados como Víctor Fuentes o Manuel Aznar Soler han dedicado importantes estudios a las publicaciones sobre el tema que se sucedían en España en aquellos años de efervescencia política. Este último se ha referido, además, a un subgénero literario de gran éxito en aquel momento:

El auge de este tipo de literatura, de estos relatos en que se narraban las impresiones del viaje - en la práctica un género literario que significó un verdadero género de época- eran una prueba contundente de la simpatía y atención con que los consumía un público lector, mayoritariamente simpatizante de aquella esperanza socialista llamada entonces Unión Soviética, un público ávido por informarse acerca de la situación política y cultural de la revolución de Octubre (Aznar Soler, 1996: 57I).

Son varios los intelectuales españoles que fueron invitados a visitar la URSS para comprobar de primera mano los cambios que la revolución había introducido en la nueva sociedad soviética. Sin embargo, no será este el caso de César Vallejo, ya que sus dos primeros viajes al país de los Soviets fueron sufragados por él mismo y no dependió de ninguna invitación oficial. El tercer y último viaje que realizó a la URSS sí lo hizo en calidad de invitado por el Congreso Internacional de Escritores en octubre de I93 I.

El i 9 de octubre de 1928 , tras unos meses marcados por la enfermedad y la penuria económica más extrema, el poeta se decide a conocer en persona ese otro mundo que se estaba fraguando en la lejana Rusia:

En medio de la convalecencia, me siento otra vez, y acaso más que nun$\mathrm{ca}$, atormentado por el problema de mi porvenir. Y es, precisamente, movido del deseo de resolverlo, que emprendo este viaje. Me doy cuenta de que mi rol en la vida no es éste ni aquél y que aún no he hallado mi camino. Quiero, pues, hallarlo. Quizás en Rusia lo halle (Vallejo, 20 I I: 254).

de libros marxistas (49 y ss.). Por otro lado, es interesante el dato de las diversas delegaciones que fueron invitadas a visitar la URSS con motivo del décimo aniversario de la Revolución, aniversario que además se convierte en el origen de la aparición de las Asociaciones de Amigos de la URSS (Garrido Caballero, 20 I 8: I 94). 
Como es bien sabido, para poder sufragar su primer viaja a la Unión Soviética, empleará el dinero del pasaje que había solicitado al gobierno peruano para ser repatriado en septiembre de 1927 . Su primera impresión es toda una conmoción: "Llegué, vi y no he acabado aún de verlo todo. Es un país formidable este de Rusia. Lenin, un genio. ¡Brutal!” (Vallejo, 20 I I: 257), comentará en una tarjeta postal a Juan Domingo Córdoba el 28 de octubre de 1928 .

El interés colectivo despertado por lo que estaba sucediendo en el país de los zares ${ }^{8}$ tiene en el caso de Vallejo una motivación clara y justificada por su acercamiento al marxismo, muy evidente durante este año 1928 (Caudet, 1988). Su amistad con José Carlos Mariátegui, fundador del PC peruano y con quien comparte una misma visión sobre la realidad, le decantará hacia la búsqueda de una solución a los problemas sociales que veía a su alrededor en una forma de organización social ajena al capitalismo. Ese capitalismo es el que había visto y sufrido tanto en su país de origen como en el de acogida, si puede llamarse así su difícil relación con Francia (en este sentido es necesario recordar los problemas que le supuso a Vallejo su afiliación al Partido Comunista Español en 1932, hasta el punto de tener prohibida la entrada en Francia durante unos meses).

Es evidente, pues, la disposición con la que Vallejo parte hacia Moscú en esta primera ocasión. La impresión recibida es un verdadero impacto, como delatan los textos de las postales que envía a sus amigos más cercanos: "Lo del Soviet es una cosa formidable. Más todavía: milagrosa. Ya le contaré en breve con detalles", le dirá a Pablo Abril de Vivero desde Moscú el 29 de

${ }^{8}$ Magdalena Garrido Caballero (2017: cap.5, p. I) reproduce la siguiente opinión de Antonio Machado conservada en el Archivo de la Guerra Civil, en Salamanca: "Moscú es hoy el foco activo de la historia [... . La Rusia actual, la gran República de los Soviets, va ganando de día en día la simpatía y el amor de los pueblos, porque toda ella está consagrada a mejorar la condición humana”. Estas palabras del poeta español podrían muy bien condensar la tesis del texto de César Vallejo que analizamos aquí. 
octubre de 1928, o a Luis Alberto Sánchez el mismo mes le escribe también desde "este milagroso país de Lenin y Tolstoy" (Vallejo, 20 I I: 255).

La necesidad de profundizar en el conocimiento de lo que ha visto en la URSS le anima a repetir el viaje un año después, esta vez acompañado por Georgette Philippart, con la que se casaría el i de octubre de i 934, para realizar un verdadero periplo por Europa, conociendo Austria, Hungría, Italia, Alemania, Checoslovaquia, además de visitar Leningrado y Moscú. Su postura sigue siendo de admiración, como le escribe a Pablo Abril de Vivero desde Leningrado en octubre de i 929: "Un gran abrazo fraternal desde este gran país, al cual dirigen las miradas todos los que, como nosotros, se dan cuenta de las pústulas sociales del régimen burgués" (Vallejo, 20 II: 274). Tanto es así, que antes incluso de llegar a París al regreso de este segundo viaje, escribirá en una carta el 27 de octubre de i 929 a su hermano Néstor: "me parece que debo volver a América a luchar y trabajar públicamente por mi país. He sufrido, repito, y no obstante me siento, mediante Dios, joven y fuerte y lleno de esperanza" (Vallejo, 20I I: 28I). Un destino colectivo organizado como el que intuye durante sus visitas a la URSS le hace añorar algo similar para su propia patria. ${ }^{9}$

De este mismo cariz son varios de los comentarios que podemos encontrar en su correspondencia y quizá puedan explicar en parte su distanciamiento de Juan Larrea (Arias, 20I4). Pablo Abril de Vivero será uno de los destinatarios de estas reflexiones, como esta que le hace el 27 de diciembre de I928:

Estoy dispuesto a trabajar cuanto pueda, al servicio de la justicia económica cuyos errores actuales sufrimos: usted, yo y la mayoría de los hombres, en provecho de unos cuantos ladrones y canallas. Debemos unirnos todos los que sufrimos de la actual estafa capitalista, para echar abajo este estado

${ }_{9}^{2}$ Este deseo de Vallejo de vincular Latinoamérica con la Unión Soviética resurgiría en 1936 de la mano de Enrique Vidal, "corresponsal y responsable de la revista mejicana Ruta en la capital soviética", quien intenta constituir una sociedad de Amigos de España y América Latina en la URSS, como señala Magdalena Garrido Caballero (20 I 7: cap. 5, p. 8). 
de cosas. Voy sintiéndome revolucionario y revolucionario por experiencia vivida, más que por ideas aprendidas (Vallejo, 20 I : 259).

Como indicábamos antes, las crónicas de sus viajes a la Unión Soviética aparecieron en diversos medios, ${ }^{\mathrm{IO}}$ siendo la colaboración más regular la que se publica en la revista Bolívar. El interés despertado por todo lo relacionado con la URSS en España provoca el ofrecimiento que Ediciones Ulises le hace a Vallejo para transformar en un libro esas crónicas. ${ }^{11}$ Como afirma Gonzalo Santonja ( I 989: I 24), "Rusia en I93 I sirvió a los editores para [...] poner un parche en su maltrecha economía, porque el libro se convirtió en un éxito: tres ediciones agotadas en cuatro meses”. De ahí que Vallejo se queje del dinero que están ganando con su libro sin que él reciba nada, como le comenta a Gerardo Diego el s de diciembre de 1932 cuando le pide "acercarse a la editorial Ulises (Olózaga, i s) y decirle al Gerente, quienquiera que fuese, que me haga el favor de enviarme inmediatamente una liquidación de las ventas de Rusia I93I, así como el saldo que, por conceptos de estas ventas, haya en mi favor. [...] Sé que siguen haciendo negocio con mi libro y no me abonan nada hace tanto tiempo" (Vallejo, 20 I : 323).

Al mismo Gerardo Diego ya le había anunciado la publicación del libro, aunque le avisaba: "En estos días salió un libro mío sobre Rusia, que no se lo envío porque no creo que le interese. Es un reportaje social, más periodístico que literario" (Vallejo, 20 I I: 3 Io). A pesar del tono indiferente

\footnotetext{
${ }^{10}$ Fernando Iwasaki (2O 3 : 1 3) ofrece una lista de estas dispersas publicaciones.

${ }^{\text {I }}$ El perfil de esta editorial es uno de los más interesantes del panorama del momento, como señala Gonzalo Santonja (1 989: 13 ) cuando afirma que el catálogo de Ulises estaba "volcado hacia el rico panorama de las literaturas europeas contemporáneas, sin desatender por ello el de la incipiente narrativa vanguardista española”. Entre los autores que publicó, además del libro de Vallejo que se analiza aquí, están las obras de Rosa Chacel, Corpus Barga, Benjamín Jarnés, Colette, Cocteau, Ehremburg, Renard o Malaparte entre otros, como se menciona en el estudio citado. Para Santonja esto es muestra de que los responsables de la editorial apostaban por el futuro y menciona las palabras que a modo de presentación se incluyeron en el primer libro editado y que terminan así: "Ediciones Ulises aspiran -y han de conseguirlo- a extender, a ampliar, a difundir por España, la voz inconfundible del espíritu contemporáneo" (apud. Santonja, I 989: I I 5).
} 
de Vallejo en esta carta, es obvio que el tema era importante para él, ya que desea publicar un segundo volumen, probablemente con algunas de las crónicas que se habían quedado fuera, pero también con los comentarios de su tercer viaje. Para este segundo libro no encontró editor, como le explica de nuevo a Gerardo Diego: "Puede que entre sus amigos editores encuentre alguno que quiera publicar mi segundo libro sobre Rusia, aquel del cual le he hablado varias veces y que yo quería editar por mi cuenta. Hasta ahora no encuentro el dinero para hacerlo y he resuelto dárselo a un editor. Si alguien quiere editarlo, hágame el favor de comunicármelo cuanto antes” (Vallejo, 20I I: 323).

La postura de Vallejo ante los acontecimientos que verá en la URSS responde a la afirmación de Jacques R. Pauwels (2002: 163) sobre el impacto que había supuesto la revolución rusa: "un puñal clavado en el costado del orden capitalista del mundo desde 1917”. El poeta peruano demuestra un verdadero empeño en la transmisión de lo que ha observado en la Unión Soviética. Sus intenciones son muy semejantes a las que se expresaron en el manifiesto de creación de la Asociación de Amigos de la Unión Soviética en I933:

Era necesario recoger todo ese ambiente difuso de curiosidad y de simpatía hacia la Unión Soviética, organizarlo y darle una base de documentación seria y actual; estudiar y exponer a la luz del día, sin ocultar ni desfigurar nada, los éxitos, las dificultades, los problemas de esta magnífica experiencia que supone para el mundo la construcción de una sociedad nueva (Garrido Caballero, 20I7: cap. 5, p. 2).

No son demasiados los investigadores que se han ocupado de Rusia en I93I, un texto que claramente resulta incómodo para los críticos que solo desean ver en Vallejo al gran renovador de la poesía en español, al verdadero vanguardista sin mezclarlo en cuestiones políticas, como si tal cosa fuera posible. Los comentarios sobre su "candor revolucionario" y sobre su nula clarividencia política (Iwasaki, 2013: I4) resultan más bien injustos, pero, 
sobre todo, pretenden resaltar lo equivocado de aquel régimen tan admirado por el poeta. No parece demasiado útil aprovechar la ventaja histórica que nos da el tiempo transcurrido desde entonces, ni la confirmación de que aquella URSS perdió finalmente la Guerra Fría (Pauwels, 2002: 296) para juzgar estas crónicas de Vallejo. Preferimos, por tanto, situarnos en otro plano para poder ver cómo la sociedad soviética, que como él reconoce en más de una ocasión en el libro no es posible captar en su profundidad con una simple visita, le permite ver con otra luz el mundo en el que vive y, sin duda, sufre.

El comienzo de Rusia en I93 I tiene el sello indeleble del poeta Vallejo:

Si el arribo a Moscú es por la mañana y viniendo del norte, la ciudad queda de lado y a dos piernas, con el Moscova de tres cuartos. Si la llegada es por la tarde y viniendo del oeste, Moscú se pone colorado y los pasos de los hombres ahogan el ruido de las ruedas en las calles. No sé cómo será la llegada a Moscú por el este y al mediodía, ni cómo será el arribo a medianoche y por el Sur. ¡Una lástima! Una falta geográfica e histórica muy grave. Porque para "poseer" una ciudad certeramente, hay que llegar a ella por todas partes (Vallejo, 2OI 3: 33).

Estas consideraciones que insertan la ciudad en los cuatro puntos cardinales no son, desde luego, gratuitas ${ }^{12}$ y no pueden por menos que recordarnos los cuatro muros de Escalas melografiadas. Visión poética por tanto que, sin embargo, dará paso a una crónica organizada por temas en las que se irán desgranando diferentes aspectos de la sociedad soviética. El sistema que usa César Vallejo será el de confrontar con la realidad europea y francesa todo lo que ve y lo que le cuentan los diferentes guías que le ayudan a sumergirse en un idioma que no conoce en absoluto. También realizará una constante comparación con Nueva York como capital indiscutida del capitalismo mundial. Sin caer en la trampa de desmentir la realidad que ve

\footnotetext{
${ }^{12}$ Sobre la importancia del número 4 véase el fundamental estudio de José Guzmán que aparece en la bibliografía.
} 
Vallejo, lo interesante es seguir esa confrontación para descubrir el profundo malestar que le producen las condiciones de vida en el mundo occidental.

Podemos decir que lo que hace Vallejo es mirar a Occidente desde la Unión Soviética; esto le permite tener un punto de comparación desde el que criticar lo que sí conoce bien y tomar conciencia de que otro mundo es posible, quizá no exactamente el de esa URSS, pero sí uno que no reproduzca el absurdo inhumano del capitalismo. De esta forma, por su libro desfilan diversos aspectos que van desde la arquitectura ${ }^{13}$ a la experiencia del amor y la familia para dejar claro que no hay nada que no pueda ser modificado, renovado, experimentado por primera vez dejando atrás cualquier tradición impuesta. Se aprecia muy bien esta actitud de Vallejo cuando describe la ciudad ideal, que no es exactamente la que ve en Moscú, de ahí las referencias al futuro: "la ciudad del porvenir ha de ser construida sólo por el socialismo, y ella misma ha de ser la más prodigiosa cristalización socialista de la convivencia humana. Concebir la urbe del provenir dentro del sistema capitalista -como lo hacen los filósofos, profetas, políticos y escritores burgueses- es un absurdo y un contrasentido" (Vallejo, 20 1 3: 40). Fiel a su cuestionamiento de las vanguardias y la modernidad, el poeta analiza los grandes adelantos conseguidos por la gran urbe del momento, Nueva York: "No es la ciudad del porvenir Nueva York. El simple espectáculo de sus maravillas mecánicas no la inviste del título ni de las cualidades suficientes para ser la urbe del futuro. Estas maravillas mecánicas constituyen apenas uno de los materiales -el más anodino- del tipo de ciudad a que aspira la humanidad" (Vallejo, 2013: 40). Más adelante explica por qué, y las razones tienen que ver, exactamente, con las manos en las que recae la posesión de los medios de producción:

${ }^{13}$ En su libro de ensayos El arte y la revolución Vallejo (1973: 44) afirma: "Estoy seguro que la mayor parte de las obras artísticas y literarias soviéticas (salvo la arquitectura), distarán inmensamente del arte socialista futuro". 
Para que las maravillas mecánicas y eléctricas de Nueva York hagan de esta urbe la ciudad del porvenir, deben ser socializadas en su creación y en su aprovechamiento. Si esto no sucede y si, por el contrario, la propiedad, los progresos de la técnica, el trabajo y los productos se basan, como hasta ahora, en la injusticia, en la explotación de la mayoría por una minoría y en la división de clases, Nueva York seguirá siendo una selva de acero en que se desarrolla el drama regresivo y casi zoológico de millones de indefensos trabajadores, devorados por unos cuantos patronos, y sus maravillas industriales - tan decantadas ya y exageradas- seguirán siendo el producto sangriento e inhumano de ese drama (Vallejo, 20I 3: 4I).

El enfrentamiento dialéctico entre lo que Vallejo ve durante sus viajes y lo que el mundo conoce como el gran modelo del mundo moderno será constante a lo largo del libro. En realidad, Vallejo quiere poner ante el lector su propia realidad y mostrarle que no es tan indiscutible y que son muchas las cosas que no solo se pueden mejorar en su propia realidad, sino que deben ser cambiadas para poder acceder a una sociedad más justa. Esta actitud se había ido perfilando desde su llegada a París, ciudad que había analizado desde una perspectiva crítica también: "las alusiones del poeta a las rápidas transformaciones de la ciudad moderna, a sus engaños y a sus defectos, aparecen en casi todos sus textos" (Ortiz Canseco, 20I4: 364). La conclusión de esta observación no podía ser otra que, como muy bien señala Marta Ortiz Canseco (20 4: 364), la desacralización de París como meca de los escritores latinoamericanos.

Que, en medio de las dos grandes guerras que sacudirán Europa, el poeta se haga eco del internacionalismo socialista es una forma de denunciar los nacionalismos burgueses causantes de dichos conflictos: "En Rusia - me dice - ningún obrero es extranjero. No hay aquí la división que se hace de las gentes en los países capitalistas, en nacionales y extranjeros. Todos los obreros están aquí en su propia casa. El único extranjero es el burgués, ruso o de cualquiera otra procedencia” (Vallejo, 20 13: 50), le explica una de las obreras de una fábrica de caramelos y chocolates que visita el poeta. Esta 
misma mujer le propondrá a su huésped, y de paso al lector, que decida qué organización social es más correcta desde un punto de vista de justicia social:

El régimen soviético es un régimen de excepciones y privilegios de las clases trabajadoras sobre las demás clases. Es lo contrario de lo que pasa en los países capitalistas, donde impera un régimen de excepciones y privilegios a favor de la burguesía y en mengua del proletariado. Ahora, a usted le toca discernir cuál de los dos sistemas se acerca más a la justicia social: el que sirve y protege a los trabajadores que crean la riqueza colectiva, o el que sirve y protege a los que no la crean y sólo se dedican a gozarla y despilfarrarla en el lujo, los refinamientos y los vicios (Vallejo, 20 I 3: 54).

El autor cierra aquí el capítulo sin ningún comentario por su parte; en realidad, la argumentación no necesita que Vallejo se manifieste en ningún sentido y deja que los lectores reflexionen con total libertad sobre lo que han escuchado. Este ejemplo nos sirve, además, para destacar otro rasgo de Rusia en I93I. En muchas ocasiones, Vallejo cede la palabra a sus guías, acompañantes, etc., permitiendo a sus lectores que puedan asistir a la experiencia de sus viajes sin necesidad de explicaciones que les guíen sobre lo que deben pensar de lo que se les muestra. Es obvio que Vallejo tiene clara su opinión, pero la reflexión que pide no es tanto la de optar por la URSS, sino la de rechazar la realidad capitalista en la que viven inmersos tanto él como sus lectores. En este sentido es interesante destacar que la reseña que escribió Leopoldo Panero (I93I: 2) señala este aspecto: “Cualquiera puede ver con los ojos de la cara que el Estado socialista está fabricando historia, mientras el Estado burgués la está consumiendo. Es decir, uno mira hacia adelante y clava sus ojos en el futuro, horizonte siempre en albor. Otro ha de tornar el rostro contemplando un paisaje desvaído, triste y exhausto". Y añade un poco más adelante: "Lo verdadero no admite partes, parcialidades. La razón no tolera la existencia - la coexistencia - de dos realidades dispares; no tolera que burgueses y proletarios tengan razón a la vez”.

En el capítulo IV el poeta visita unos laboratorios dedicados a analizar y estudiar los efectos que el trabajo provoca en el ser humano. Las 
conclusiones son espeluznantes: "Sabemos ya que el trabajo deforma los leucocitos, y que de esta deformación proviene, hasta nueva orden, la fatiga del obrero" (Vallejo, 20 1 3: 63; la cursiva es del autor). El objetivo es, pues, suprimir la fatiga. Cuando Vallejo pregunta a su acompañante si existe algún país que haya investigado sobre este asunto, le responden que en cierta medida se han llevado a cabo estudios en pequeña escala y solo en Estados Unidos, en las fábricas de Ford. ${ }^{14}$ De nuevo las diferencias de los dos enfoques se hacen patentes: "Sin embargo, su interés por proteger y conservar la salud de los obreros, y con la de ellos, la de la humanidad entera, está sofrenado por sus intereses patronales y, lo que es peor, por la esencia misma de la explotación capitalista, que descansa y está condicionada en la ruina del proletariado" (Vallejo, 201 3: 65).

Es curioso cómo algunos de los argumentos que se utilizan al contrastar la organización del trabajo en una sociedad socialista con la que tiene lugar en una sociedad capitalista siguen siendo vigentes, o mejor aún, se han actualizado con las teorías actuales sobre la formación continua de los trabajadores y la necesidad de que vivan en constante renovación para poder adaptarse a los constantes cambios que les exigirá su vida laboral. Lo que hoy en día se describe como un proceso positivo y necesario para la realización no solo laboral sino humana del ciudadano es duramente criticado en el libro de Vallejo:

El fabricante vive con la constante preocupación de vencer a sus concurrentes, vendiendo más barato, con mejor material, etc. Para obtener estos resultados, no pierde tiempo en intensificar la productividad de su fábrica. Dos métodos, entre todos, le sirven para el caso: perfeccionar al infinito su maquinaria para producir más rápido y para reducir el número de obreros, y forzar a estos a adaptarse continuamente a unos aparatos y a una técnica que cambian y se perfeccionan todos los días (Vallejo, 201 3: 69).

${ }^{14}$ Es muy interesante que otra escritora peruana, Rosa Arciniega, haya dedicado también una novela a analizar las condiciones de trabajo en una fábrica automovilística en Estados Unidos. La novela se titula Mosko-Strom y se publicó en i 934. Para un análisis de esta obra y otras de la misma autora muy relacionadas con lo que se comenta aquí véase Arias (2013). 
Y termina explicando el agotamiento físico y mental que esto supone para el trabajador. Un análisis teórico de estos presupuestos en el ensayo de Marshall Berman Todo lo sólido se desvanece en el aire demuestra la actualidad de la visión que presenta Vallejo. La alternativa que se le ofrece al observador en el nuevo sistema es que "el trabajador ha de ejecutar su labor del modo más automático posible. Sus actos deben realizarse por sí solos y no deben costarle ningún esfuerzo de raciocinio. La técnica socialista deja intacta e intocada la vida espiritual del trabajador" (Vallejo, 2013: 70) ¿Y todo esto para qué? Pues para algo que difícilmente se asocia con el materialismo histórico y que, sin embargo, está ahí desde sus inicios: soñar, como le dicen a Vallejo, y que es imposible no relacionar con aquel mandato que incluso Cortázar había reproducido en la cubierta de Último round: "Hay que soñar, pero a condición de creer seriamente en nuestro sueño, de examinar con atención la vida real, de confrontar nuestras observaciones con nuestro sueño, de realizar escrupulosamente nuestra fantasía” (Lenin, I97 I: 17).

Después vendrán referencias a las causas de las grandes crisis económicas mundiales (no olvidemos que en 1929 se había producido una de las más graves que se habían conocido hasta el momento) y de nuevo la perspectiva de Vallejo vuelve a ser contrastiva entre lo que el mundo occidental le ofrece al trabajador y lo que podría ser una forma diferente de vivir y organizar el mundo del trabajo. La esencia capitalista de la libertad de mercado, es decir, de la competencia como razón última de la economía, deviene en una carrera enloquecida hacia ningún sitio, ${ }^{15}$ que deja sembrado el camino de víctimas inocentes: "El apetito patronal de producir más y mejor

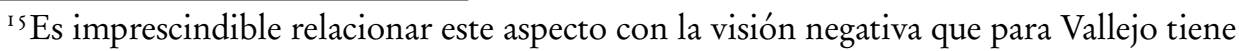
la competitividad deportiva y que él liga a la Primera Guerra Mundial (Ortiz Canseco, 20I4: 370). Lejos de ello, el autor afirma: "Yo no vivo comparándome a nadie ni para vencer a nadie y ni siquiera para sobrepujar a nadie. Yo vivo solidarizándome y, a lo sumo, refiriéndome concéntricamente a los demás, pero no rivalizando con ellos” (Vallejo, 2002, I: 477). 
en menos tiempo y gastando menos, para vencer así a sus concurrentes en el mercado mundial, lleva al fabricante a una carrera desatentada en materia de racionalización" (Vallejo, 2013: 72). La primera consecuencia la sufren los obreros que quedan desempleados, mientras "los fabricantes siguen ganando". Frente a este enloquecido mecanismo, "En el régimen socialista, nadie quiere vencer a nadie en competencias del mercado" (Vallejo, 20 I 3: 73) y, de esta manera, "No hay lugar entonces a stockage ni a ninguna otra crisis de superproducción. Toda la producción se ajusta, en cantidad y calidad, a las necesidades sociales del momento. En otros términos: el consumo está en perfecto equilibrio con la producción” (Vallejo, 2013: 74). Una vez más, son palabras de los guías que acompañan al poeta, mientras este se limita a preguntar y dejar hablar sin expresar ninguna conclusión, que por otra parte resulta innecesaria. De estas conversaciones se va destilando poco a poco el principio que rige no solo la economía, sino también la organización de toda la sociedad: "[el] aumento del bienestar y la riqueza comunes" (Vallejo, 2OI3: 75).

Como estamos viendo, el autor procura situarse en un segundo plano, permitiendo a sus informantes expresarse con total claridad. Tanto es así, que, en determinado momento, informa al lector que su siguiente acompañante e intérprete es una mujer poco simpatizante con el nuevo régimen instaurado en su país y mucho más adicta a la antigua Rusia zarista, lo que "sirve a maravilla el carácter imparcial que me propongo dar a mi reportaje" (Vallejo, 2013: 83). La única reseña que se publicó sobre el libro enmienda esta afirmación del poeta: "Este es un libro verdadero sin ser un libro imparcial” (Panero, I93 I: 2). Y lo explica así:

En este ocaso de la imparcialidad marca un punto de partida hispánico el libro de César Vallejo "Rusia en i 93 I”. Es Vallejo quizá el primer escritor de palabra española que se acerca a Moscú desdeñando la imparcialidad. O lo que es igual: desdeñando la interpretación sentimental de una revolución proletaria. Ello le permite mostramos el proceso vivo de Rusia, encajándolo fuertemente en la historia, poniendo ante los ojos los fenómenos de la revo- 
lución obrera como conectados por una misma savia profunda. Su ademán sencillo, objetivo y antisentimental frente a la vida soviética le hace percibir por pura razón la historia que fluye bajo sus plantas. Por pura razón, que es pura idea: razón histórica $=$ idea de libertad.

Pero Vallejo no se ocupa solo del mundo del trabajo, como anunciábamos. También el ocio le interesa y también ahí vuelve a mirar hacia su realidad: "En París y en las demás urbes capitalistas, la sociedad ha trazado y mantiene una línea profunda de separación entre los placeres y los trabajos, entre los lugares de diversión y los de labor. En ciertos focos ciudadanos y a ciertas horas o días, sólo es posible el solaz exclusivo y sin mezcla de trabajo creador. En otros núcleos y en otros momentos, sólo es posible el trabajo, con exclusión absoluta del placer” (Vallejo, 2013: 93). Pero ¿podría ser de otra manera, podrían existir vinculados el esfuerzo y el placer creador? Qué distinta esta propuesta de un ocio que anula cualquier ingrediente de creatividad, convirtiendo a los ciudadanos en meros consumidores y no en parte activa de un tiempo libre que podría convertirse en faceta indispensable de su desarrollo como constructores de la sociedad en la que viven.

¿Y la literatura? "No hay literatura apolítica; no la ha habido ni la habrá nunca en el mundo”. Y encontramos, entre las opiniones que reproduce Vallejo de una tertulia sobre el tema, gérmenes de sus propios poemas:

La inteligencia trabaja y debe trabajar siempre bajo el control de la razón. Nada de superrealismo, sistema decadente y abiertamente opuesto a la vanguardia intelectual soviética. Nada de freudismo ni de bergsonismo. Nada de complejo, libido, ni intuición, ni sueño. El método de creación artística es y debe ser consciente, realista, experimental, científico (Vallejo, 20 I 3: 99).

Y así, el poeta escribirá ese impresionante poema, cuyas primeras estrofas nos dicen:

Un hombre pasa con un pan al hombro

¿Voy a escribir, después, sobre mi doble?

Otro se sienta, ráscase, extrae un piojo de su axila, mátalo

¿Con qué valor hablar del psicoanálisis? 
Otro ha entrado en mi pecho con un palo en la mano

¿Hablar luego de Sócrates al médico?

Un cojo pasa dando el brazo a un niño

¿Voy, después, a leer a André Bretón?

Otro tiembla de frío, tose, escupe sangre

¿Cabrá aludir jamás al Yo profundo?

Otro busca en el fango huesos, cáscaras

¿Cómo escribir, después del infinito?

Un albañil cae de un techo, muere y ya no almuerza

¿Innovar, luego, el tropo, la metáfora? (Vallejo, i 996: 535)

Porque "el escritor revolucionario tiene conciencia de que él, más que ningún otro individuo, pertenece a la colectividad y no puede confinarse a ninguna torre de marfil ni al egoísmo" (Vallejo, 2013: гоo). Y, una vez más, el poeta no pierde ocasión de criticar a esos escritores contra los que ha escrito algunos de sus ensayos más brillantes, tanto los escritores librescos, alejados de la realidad cotidiana, como los bohemios, dedicados solo a sus propios placeres. Sin embargo, como señala Rafael Gutiérrez Girardot ( 1993: 58), César Vallejo era consciente de cómo el contexto podía determinar una expresión literaria producida en el ámbito de la Unión Soviética o en el ámbito de las sociedades capitalistas occidentales. El propio poeta había afirmado: "Hay la literatura revolucionaria rusa y la literatura revolucionaria que combate dentro del mundo capitalista. Los objetivos, método de trabajo, técnica, medios de expresión y materia social varían de la una a la otra" (Vallejo, i 973: is6).

$\mathrm{Y}$ de la literatura nos vamos al amor, un amor que raramente existe entre nosotros, dice Vallejo refiriéndose al mundo capitalista (Vallejo, 20 I 3 : Ior): "llamamos amor a una simple simpatía, hija directa de un interés económico o de cualquier otra especie, pero que nada tiene que ver con el 
mundo afectivo". El poeta dedica bastante espacio a comentar y describir los rasgos que en la sociedad que él habita tiene este sentimiento, sin hacer diferencia entre hombres y mujeres. En su crítica se olvida de relacionar la cosificación de la que es objeto el ser amado con el funcionamiento del patriarcado. Aunque los ejemplos que utiliza demuestran la posición subalterna de la mujer en la sociedad no pone en relación esta situación con el funcionamiento del sistema capitalista como expresión de ese patriarcado.

Frente a todo eso, lo que ve son parejas que se unen, viven juntas y solo el amor puede explicar unos vínculos que no descansan en ningún beneficio material. Incluso la atracción sexual entre ellos tiene que ser "fuerte, sana, profunda" (Vallejo, 2013: I04) para poder explicar la duración de esas uniones. Observa, además, la igualdad entre hombre y mujer y la ausencia de una división entre los comportamientos públicos y privados, anulando esa frontera tan clara e infranqueable en la sociedad capitalista, donde ambos mundos parecen divididos y situados en dimensiones completamente ajenas entre sí (Habermas, 2007: i 5 I-I 59). Pero la identificación que Vallejo hace de este problema y su distinta presentación en la URSS no hace sino avalar esta afirmación: "el espacio público y el privado no son consustanciales a la existencia humana, sino que ambos forman parte de la organización histórica del poder y la subordinación política y social entre los diferentes sujetos y grupos que devienen de ella" (Ochoa Crespo, 2016: I7 I).

Estas nuevas formas de relación entre los sexos vuelven a poner en entredicho la sociedad construida a partir del sistema capitalista y patriarcal, insistimos, aunque Vallejo no lo mencione así. De esta forma, "el matrimonio es antisocialista, antirrevolucionario. El matrimonio, como la poligamia - aunque esto parezca una contradicción-, es una forma genuina de la sociedad organizada en clases. El matrimonio es una de las instituciones más reaccionarias y más salvajes de la historia" (Vallejo, 2013: 195). También queda destruida la familia tal y como se concibe en la sociedad burguesa y es 
curioso que esa destrucción pasa necesariamente por el fin de las jerarquías patriarcales y por la ruptura, otra vez, entre la frontera privado/público (Vallejo, 2013: 199; también son importantes 200 y 201). Las consecuencias de esa división infranqueable son muy serias en la sociedad burguesa, donde los ciudadanos se desentienden del funcionamiento de su país: "en los países capitalistas o feudales la economía y la política son manejadas y dirigidas por unos cuantos y al servicio de unos cuantos" (Vallejo, 2013: 207). Las siguientes palabras de Vallejo demuestran lo poco que ha cambiado la sociedad actual comparada con aquella que observaba el poeta desde la distancia que le da la URSS:

$¿ Y$ quién se ocupa en Inglaterra de mejorar y humanizar el régimen penal? ¿Un transeúnte cualquiera? No. Se ocupa de ello sólo el diputado, el ministro, el lord, el magistrado o el profesor de Cambridge o de Oxford. Esto no concierne al simple transeúnte sino a la hora de entrar en prisión por haber dicho más verdades al equívoco Príncipe de Gales, o por haber condenado públicamente la guerra de las patrias burguesas. Y por este camino, todos los transeúntes del mundo capitalista - que son masa- han llegado a la conclusión de que la economía y la política no pasan de ocupaciones de iniciados, remotas, borrosas, de las que la multitud puede prescindir sin dificultad. En suma, los fenómenos políticos y económicos burgueses consienten y exigen la intervención popular solo para hacerla sufrir sus consecuencias y para echar sobre los hombros de las masas el aparato de la producción, base de esos fenómenos, pero de ningún modo para encauzar y dirigir a estos. Los profesores y estetas burgueses defienden, consciente o inconscientemente, esta misma realidad (Vallejo, 201 3: 208).

Entre las facetas de la sociedad soviética que verá Vallejo está también otro de sus grandes intereses como encarnación de la modernidad (Ortiz Canseco, 20I4: 37I): el cine, en concreto los estudios en los que trabaja Eisenstein. En su libro dará cuenta de aquellos aspectos del cine soviético que más se alejan del que se está haciendo en Europa o en Estados Unidos. Le interesará sobre todo la utilización de actores no profesionales, "sin formación artística”, como dice en una nota a pie de página, con la peculiar relación que se establece entre ficción y realidad en la propia producción de la película. Por esto le interesará tanto también todo lo relacionado con el 
cine de Vertof y con, en palabras de Eisenstein que reproduce Vallejo, un "arte [que] ha cesado de serlo y se encamina a la meta de devenir la vida misma” (Vallejo, 2013: 213).

Vallejo, que fue maestro, se interesa también por conocer el funcionamiento de las escuelas, tanto lo que se enseña en ellas como los métodos utilizados. En sus preguntas se trasluce cómo echa de menos un método socrático ajeno a la metodología soviética. Pero, fiel a su postura, introduce también la justificación para no utilizarlo. Sin duda, esta parte de Rusia en I93 I debe leerse a la luz de Paco Yunque. Cómo evoca el final de su visita a una escuela infantil el poema "España, aparta de mí este cáliz" y a esos niños que tendrán que salir a buscar a la madre España, aquella que Vallejo no llegó a ver caer: "El himno socialista en boca de los niños proletarios nos despierta una emoción desconocida y nos hace pensar forzosamente en la humanidad del porvenir" (Vallejo, 2013: 238).

Para terminar este acercamiento al texto del poeta peruano, nada mejor que recordar el debate al que asiste en el Museo Politécnico entre un variado público que incluye campesinos, obreros, ingenieros, funcionarios, hombres de ciencia y "todos los matices de la sociedad soviética” (Vallejo, 2013: 2 I 5) y un delegado del partido comunista yanqui ante la Komintern. Lo que se enfrenta aquí es la experiencia real del público y la visión que les ofrece del mundo capitalista el ponente. Un mujik, un campesino, quiere saber cuál es la diferencia entre vivir en un país capitalista y vivir en el país del Soviet y comenta que a él le han dicho que en los países capitalistas se vive mejor que en la URSS; el conferenciante contesta:

Yo he vivido en los Estados Unidos, en Alemania, en Francia. En todos estos países hay lo que había en Rusia antes de la revolución. Hay allí ricos y pobres, señores y siervos, patronos y obreros. Hay también personas de levita, con bastón, piedras preciosas y carruajes lujosos, y hay otras vestidas de andrajos. Hay unos que se agachan y tiemblan de miedo ante otros, que son los generales, popes, propietarios, altos empleados y muchas otras gentes de cuello duro. Hay también muchos goces y placeres para unos, y para los demás solo miseria y dolor. En esos países hay grandes placeres, pero son 
únicamente para unos cuantos. Hay también allí unos que van a la ópera y otros que ni siquiera la conocen. Por último hay unos que trabajan y no es para ellos lo que hacen con su trabajo, mientras que hay otros que nunca trabajan y que, sin embargo, toman todo lo que los otros producen con su trabajo... (Vallejo, 201 3: 230).

Reflexionando sobre cómo ha cambiado su vida, que ya no tiene que agachar la cabeza ante nadie, que su trabajo tiene un horario que no puede ser superado, que puede ir al cine, al teatro, a un estadio deportivo y sentarse donde le apetezca, como todos los demás, que el trigo que cultiva se reparte entre todos los que lo cultivan, el mujik llega a la conclusión que unos años después expresaría tan bien en un poema Nicolás Guillén al analizar cómo otra revolución había modificado su vida de mulato marginado en una sociedad racista y explotadora: “Tengo lo que tenía que tener”.

El libro que César Vallejo escribió a partir de su experiencia en la URSS intenta reunir los diversos aspectos de la sociedad soviética observados en sus viajes. A pesar de su evidente postura ante lo que ve, el autor busca sobre todo una reacción del lector para obligarle a replantearse la realidad en la que viven los países occidentales. De esta forma, el objetivo del libro no sería tanto una exhibición de las conquistas del nuevo país como ofrecer una herramienta que haga evidentes los mecanismos de explotación del capitalismo y la ineludible necesidad de modificar esa situación. En I93 i la URSS que conoce Vallejo le permite encontrar una alternativa y confirmar la idea de que otro mundo es posible. La posterior caída de aquella sociedad no quita ninguna vigencia a la tesis defendida por el autor acerca de la denuncia que lleva a cabo del mundo en que vive y que sigue, hoy en día, necesitando una alternativa y un viraje hacia una sociedad más humana.

\section{BIBLIOGRAFÍA}

A legría, Ciro (1978), "El César Vallejo que yo conocí”, Perfil de César Vallejo, Buenos Aires: Litoral, pp. I36-1 37.

A rias Careaga, Raquel (2O 3), "Rosa Arciniega y la novela social: las trampas del progreso”, César de Vicente Hernando (ed.), Una generación perdida. El tiempo de la literatura de avanzada (1925-1935), Doral: Stockcero, pp. 171-196. 
Arias Careaga, Raquel (2014), "Una relación literaria: de César Vallejo a Juan Larrea”, Selena Millares (ed.), En pie de prosa. La otra vanguardia hispánica, Madrid/Frankfurt: Iberoamericana/Vervuert, pp. 9-34.

Arias Careaga, Raquel (2017a), "Diálogos entre América y España a través de la revista Bolívar", Selena Millares (ed.), Diálogos de las artes en las vanguardias hispánicas, Madrid/Frankfurt: Iberoamericana/Vervuert, pp. I I-33.

Aznar Soler, Manuel (i 996), "Política y literatura en los ensayos de Max Aub", Cecilio Alonso (ed.), Actas del Congreso Internacional "Max Aub y el laberinto español”, Valencia: Ayuntamiento de Valencia, pp. 568-6i4.

Berman, Marshall (I 998), Todo lo sólido se desvanece en el aire: la experiencia de la modernidad, Madrid: Siglo XXI.

Caudet, Francisco (1 988), "César Vallejo y el marxismo", Cuadernos Hispanoamericanos. Homenaje a César Vallejo, 456-457, pp. 779-80 I. Disponible en file://C:/Users/Usuario/Downloads/ cesar-vallejo-y-el-marxismo.pdf [consultado el 2i de abril de 2017].

Garrido Caballero, Magdalena (2017), Las relaciones entre España y la Unión Soviética a través de las Asociaciones de Amistad en el siglo XX, Murcia: Universidad de Murcia. Disponible en http://hdl.handle.net/I IO2OI/I 86. [Fecha de consulta diciembre 20I7].

Garrido Caballero, Magdalena (20 I 8), "Entrevista", Cultura de la República. Revista de Análisis Crítico, 2, 194-199. DOI: http://dx.doi.org/Io.15366/crrac20 I 8.2. Disponible en: ://revistas.uam.es/index.php/crepublica/issue/view/803.

Gutiérrez Girardot, Rafael (i 993), “César Vallejo y Walter Benjamin”, Cuadernos Hispanoamericanos, 520, pp. 55-72.

Guzmán, José (2007), Tahuashando. Lectura mestiza de César Vallejo, Santiago de Chile: LOM.

Habermas, Jürgen (2007), The Structural Transformation of the Public Sphere. An Inquiry into a Category of Bourgeois Society, Cambridge: Polity Press.

Iwasaki, Fernando (20 1 3), "Las crónicas rusas de César Vallejo", César Vallejo, Rusia en I93 I reflexiones al pie del Kremlin), Sevilla: Renacimiento, pp. 9-26.

Len in, Vladimir Ilich (I97 I), La literatura y el arte, Moscú: Editorial Progreso.

Осhо Crespo, Pedro (2016), "El desequilibrio universal no mengua. Sofía Casanova ante el espacio público en la década de 1920", Espacio público y espacio privado, Madrid: Abada, pp. I7 I-2 Io.

Ortiz Canseco, Marta (20 I4), "Crónicas desde París: modernidad y capitalismo en César Vallejo”, Anales de Literatura Hispanoamericana, 43, pp. 359-376.

Panero, Leopoldo ( I93 I), "Rusia y la imparcialidad. En torno a un libro de César Vallejo", El Sol, 29 de septiembre, p. 2.

Pauwels, Jacques R. (2002), El mito de la guerra buena. EE.UU. en la Segunda Guerra Mundial. Hondarribia: Horu.

Santonja, Gonzalo (1989), La República de los libros. El nuevo libro popular de la II República, Barcelona: Anthropos.

Vallejo, César (1 973), El arte y la revolución, Lima: La Mosca Azul.

Vallejo, César (1 996), Poesía completa, Antonio Merino (ed.), Madrid: Akal.

Vallejo, César (2002), Artículos y crónicas completos, Jorge Puccinelli, (ed.), 2 vols. Lima: PUCP.

Vallejo, César (20 I I), Correspondencia completa, Valencia: Pre-Textos.

VAllejo, César (201 3), Rusia en I 93 I (reflexiones al pie del Kremlin). Sevilla: Renacimiento.

recibido: febrero de 2019

aceptado: julio de 2019 